\title{
EFFECTIVE USE OF OFFSITE MANUFACTURING FOR PUBLIC INFRASTRUCTURE PROJECTS IN AUSTRALIA
}

\author{
Tharaka Gunawardena ${ }^{1 *}$, Priyan Mendis ${ }^{1}$, Tuan $\mathrm{Ngo}^{1}$, Behzad Rismanchi ${ }^{1}$ and Lu Aye ${ }^{1}$ \\ ${ }^{I}$ Department of Infrastructure Engineering, The University of Melbourne, Parkville, VIC 3010, Australia \\ *Corresponding author:tgu@unimelb.edu.au
}

\begin{abstract}
Prefabrication and offsite manufacturing have featured in various forms in an in-situ based construction industry for many decades. Scarcity of both human and material resources is challenging the future of traditional construction practices. Due to its many benefits such as speed of project delivery, minimum work on site, minimised construction waste and higher quality assurance, offsite manufacturing is gradually evolving into an essential technology in the construction industry. As a result of re-cent government initiatives, Australia is seeing a considerable increase in the use of offsite manufacturing and prefabricated modular technologies in delivering public infrastructure projects such as schools, healthcare facilities, and public transport facilities. Such projects are ably supported by academic research collaborating with the industry to ensure that the outcomes keep improving to achieve the highest quality and functionality. This paper discusses how multidisciplinary research addresses issues such as structural performance, construction technology, design for manufacturing and assembly and indoor environ-mental quality for the delivery of such public infrastructure projects. These projects have set an example in how offsite manufacturing supported by academic research can be beneficial for effectively delivering the greater good to the society.
\end{abstract}

\section{Introduction}

Two of the main issue in the current construction industry in Australia are the diminishing availability of skilled labour and the increasing cost of construction. Off-site manufacturing of building components and prefabricated modular building systems offer an opportunity to replace the need for labour with a supply of upskilled and trained technicians or other automated means such as production lines and robots. Such building units (modules) are made in a factory production facility with thorough quality checks and a large saving of time. It also provides a method to reduce construction waste and thereby, with better planning, reduce the overall costs of construction. The cost of construction is also largely benefited via economies of scale that result from many such units being repetitively built in a factory.

Off-site manufacturing offers a unique opportunity to commence the construction even before the site is available. The fabrication can proceed concurrently with on-site activities such as demolition works, foundation works and other civil works and site preparation activities. On occasions where there is a repetition of building components owing to certain similarities in projects, most structural frame fabrications can commence even while waiting for approvals for the overall design.

Fast growing construction environments in many countries are increasingly resorting to prefabricated technologies. As such the Australian construction industry too, adapted prefabrication in a large way over the past decade (Navaratnam $\mathrm{S}$ et al., 2019). In recent times as well as in the past, construction in Australia has used various forms of prefabrication from time to time especially in warehouses, bridges and road works. However, the need for more prefabrication to be an essential part of construction in Australia is already inevitable. Many major cities in Australia are currently experiencing a vast increase in population mainly due to immigration. As a result, there is a nationwide drive for more public infrastructure projects. Therefore, this paper discusses how off-site manufacturing has been used in Australia delivering public infrastructure projects as highquality outputs and fast installations. It also includes a discussion on how ongoing academic research has assisted these projects in a positive manner.

\section{Background to Offsite Manufacturing}

Off-site manufacturing has featured in building construction for many years in various forms. Dry wall systems, structural insulated panels (SIP), prestressed beams, prefabricated roof trusses, prefabricated reinforcement cages etc. are such examples. Lusby-Taylor et al. (2004) identified various forms of prefabricated construction in five categories according to the way it is manufactured and assembled on site as;

1. Modular (Volumetric) construction: Production of three-dimensional units including finishes in controlled factory conditions prior to transportation to site.

2. Panelised construction: Flat panel units (flat-packs) are produced in a factory and assembled on-site to produce a three-dimensional structure. This method usually leaves some finishes to be done on-site after assembly. 
3. Hybrid (Semi-volumetric) construction: combines both panelised and modular approaches. Typically, modular units (also known as "Pods") are used for the highly serviced and more repeatable areas such as kitchens and bathrooms, with the remainder of the dwelling or building constructed using panels

4. Off-site manufactured sub-assemblies and components: covers approaches that fall short of being classified as systemic off-site manufacturing, but which utilise several factory-fabricated innovative subassemblies or components in an otherwise traditionally built structural fabric, e.g. roof cassettes, pre-cast concrete foundation assemblies, but excluding window, door sets, roof trusses.

5. Non-OSM (Off-site manufactured): This category is intended to encompass schemes utilising innovative housing building techniques and structural systems that fall outside the OSM categories.

The top four in the abovementioned list belong to what is broadly known as Off-site manufacturing (OSM). Of these, volumetric (modular) construction has become the more prominent form of modern prefabricated buildings especially in Australia.

The graphic in Figure 1 highlights the main two benefits of volumetric (modular) construction in the form of reduced labour and construction time compared to other conventional and modern methods of construction. Some of the other benefits and features of prefabricated modular construction are as follows;

- The modules can incorporate all components of a building including stairs, lift shafts, facades, corridors and services.

- The modules can be mass produced in a quality-controlled production facility. A unit's length, width and height may vary from project to project.

- There is minimal work on site to complete the buildings as the façade and interiors themselves form parts of modules. This enables the construction process to move away from being a labour-oriented operation to a more processoriented manufacturing and assembly process resulting in building sites with less congestion and pollution.

- Most material waste can be recycled into being parts of other structures or support systems inside a factory reducing construction waste even further.

- The modules can be removed from the main structure for future reuse or relocation. The reusability of prefabricated modules creates a large impact on having a much lower life cycle energy (Aye et al., 2012).

- Modular construction at present reduces construction time by over $50 \%$ from a site-intensive building (Lawson et al., 2012). This ensures that the Client of the project starts generating revenue from the project much faster and invests in the opportunity costs of having a different construction technology in earning further income. This would be very advantageous for a country such as Sri Lanka where a lot of public infrastructure projects initiate through foreign loans.
Figure 1: On-site labour requirement and construction duration of volumetric (modular) construction compared to other types of construction (National Audit Office, UK, 2005)

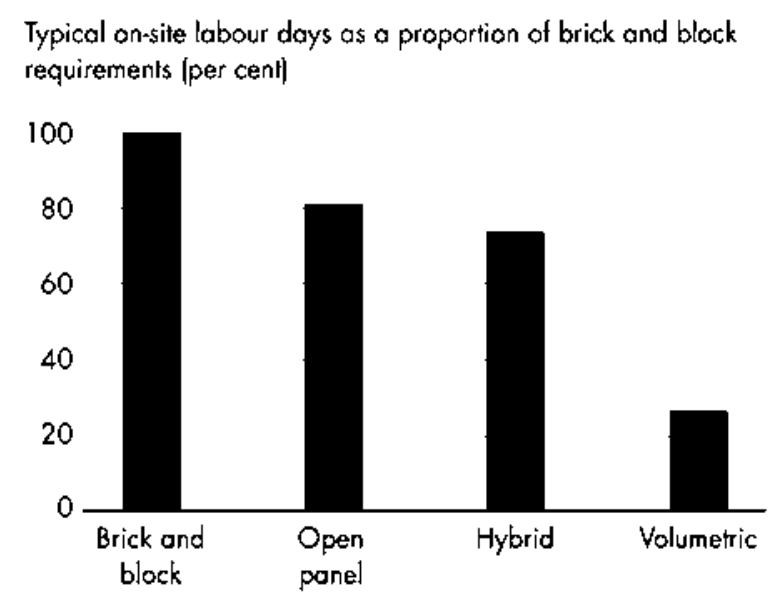

Typical construction period as a proportion of brick and block requirements (per cent)

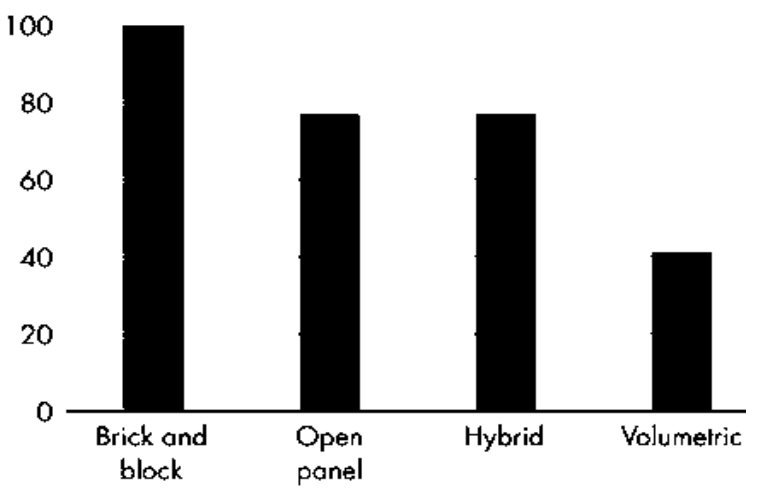

\section{Examples of Public Infrastructure Projects Completed Using Offsite Manufacturing in Australia}

\subsection{Public Schools}

The Permanent Modular School Buildings Programme (PMSB), by the Victorian School Building Authority (VSBA) of Australia has resulted in the initiation of the replacement of old school buildings with newly built modular classroom buildings in one hundred public schools around Victoria, Australia. These buildings are built in factories and brought to site to install. New buildings are provided to these schools with minimum disruption to normal activities. Usually, most demolition works of old buildings would occur during school holidays, and by the time the students return after the holidays, 
Figure 2: New modular schools built by the permanent modular school buildings (PMSB) programme of Victorian School Building Authority of Australia in 2018 - (Victorian School Building Authority [VSBA], (C) State of Victoria, Department of Education and Training, 2018)

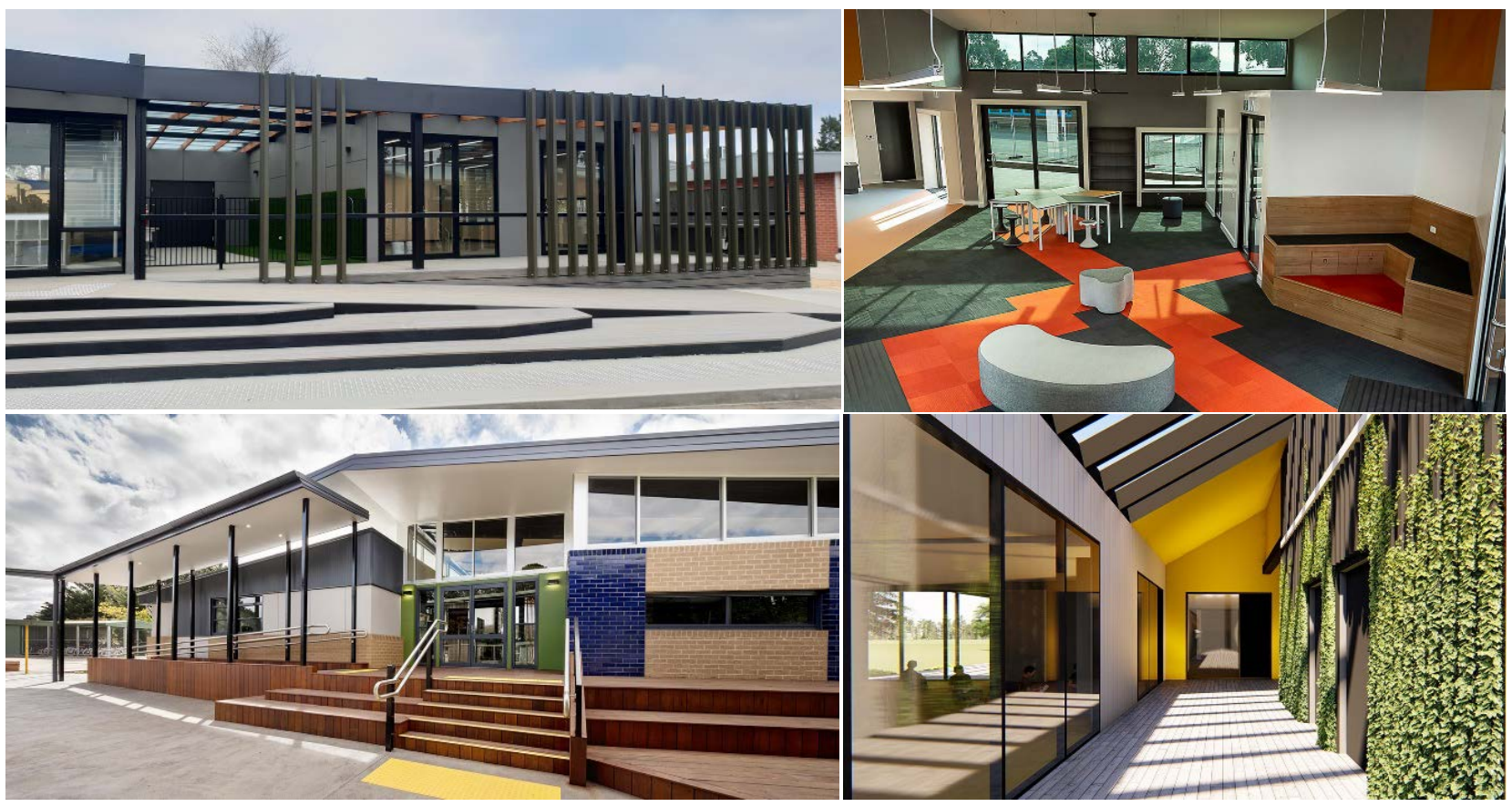

they would have a fully functioning new classroom building ready to be used. Figure 2 shows some of the exterior and interior images of those classroom facilities newly built by the PMSB programme. The first two rounds of the programme in 2018 delivered 27 such new school buildings in Victoria, Australia using offsite manufactured buildings while 21 more schools are being delivered currently in the following rounds.

Similarly, in the USA, traditionally built public schools that have aged and are currently below standard levels of operability are being replaced with new modular classrooms. However, this process is mainly carried out by private ventures such as the Gen7 modular programme by AMS (American Modular Systems) (Gen7, 2018). Similar tendencies have been shown in other countries such as Sweden and Germany. Some of these modular school buildings also facilitate auditoriums, kitchens, canteens, toilets and libraries in addition to the standard classrooms. Since they are built in a qualitycontrolled factory setup, the functionality and indoor environmental quality of these classrooms are observed to be of a very high standard.

\subsection{Public Transport Infrastructure}

Prefabrication has been a common feature in transport infrastructure in many parts of the world in the form of precast concrete bridges and other road constructions. However, due to the recently developed popularity of offsite manufactured modular buildings, they have helped in completing many building components related to public transport works very rapidly. In that regard, Public Transport Victoria (PTV) in
Australia has extensively used offsite manufactured modular buildings to build railway stations in many of the suburbs covered by the Melbourne metro railway network (Figure 3). The greatest advantage here has been the fact that the new railway stations were able to be installed with minimum

Figure 3: Railway stations built in Melbourne, Australia using prefabricated modules and other forms of off-site manufacturing (Prebuilt Pty. Ltd., 2018)

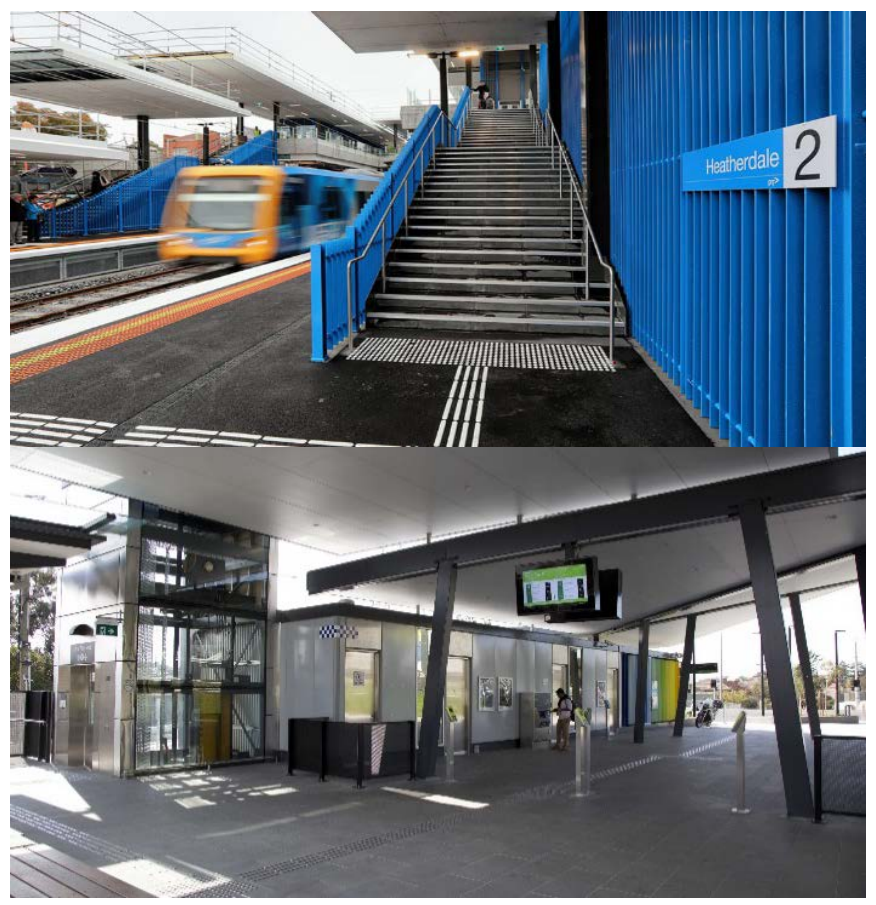


Figure 4: Healthcare facility in Melbourne, Australia built using prefabricated modules (exterior - top, interior - bottom) (Prebuilt Pty. Ltd., 2018)

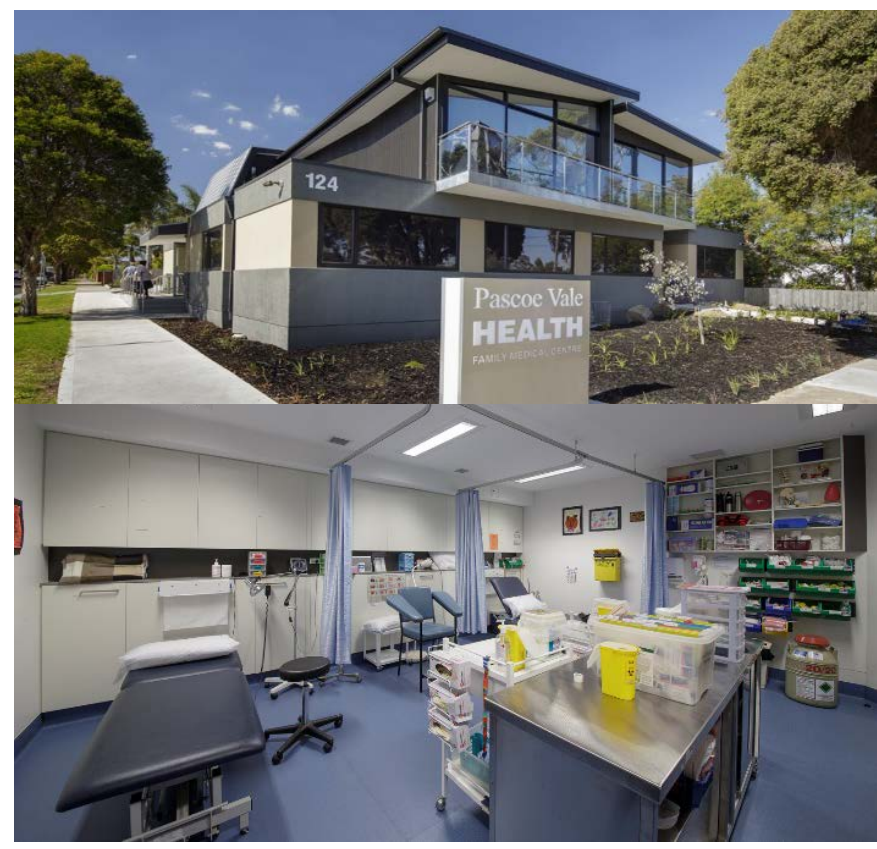

Figure 5: A police station in Melbourne, Australia built using prefabricated modules (Prebuilt Pty. Ltd., 2018)

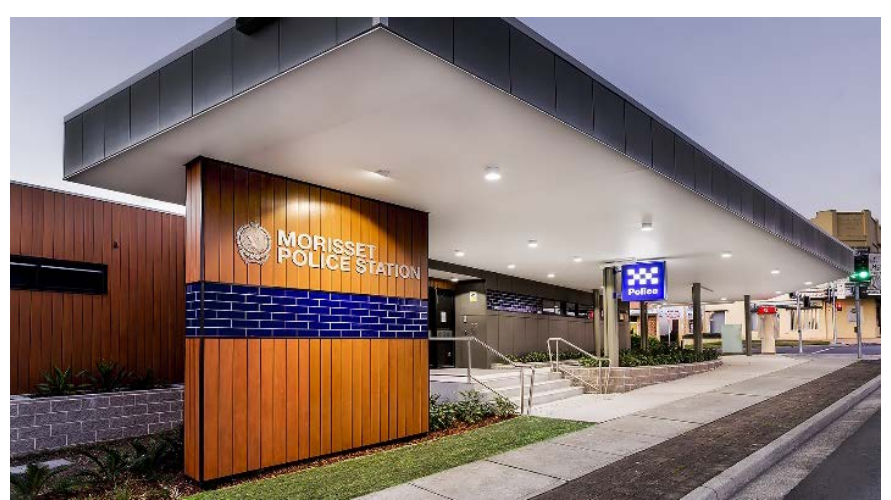

Figure 6: A correctional facility (prison) built in Australia using prefabricated modules (Modular Building Systems, 2018)

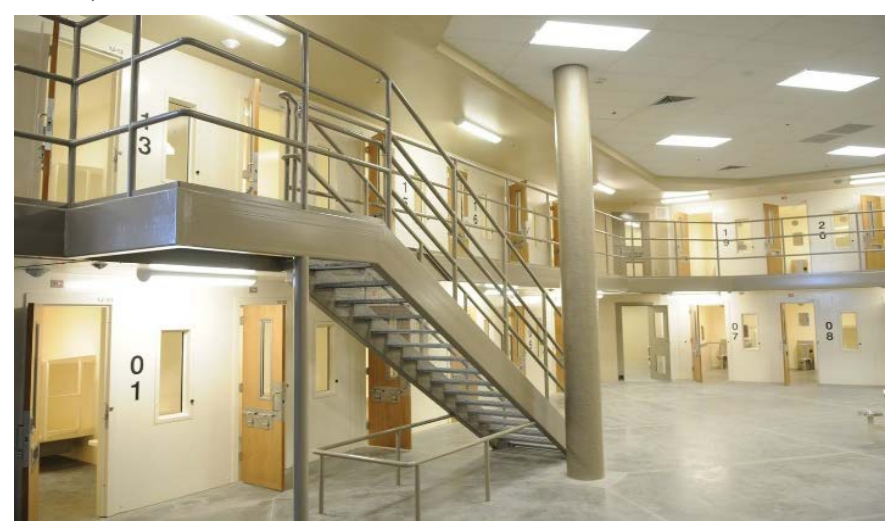

disruption to the normal operation of the railway network. Most modules could be installed during off-peak hours and weekends within a matter of days where some had actually taken only one day. Where new stations were being built, the civil work such as laying new rail tracks etc. could be carried out without any disruption while the modules were being installed.

\subsection{Public Healthcare Facilities}

Countries such as India had initially taken a pioneering role in building hospital facilities using prefabricated modular construction. The main feature that has been an advantage is the repetitive nature of designs required for hospitals. Offsite manufacturing provides great economies of scale in constructing repetitive designs in high volumes.

Similarly, Australia (Figure 4) has also built healthcare facilities using off-site manufactured modules. Due to the repetitive nature of the design of hospitals, only a limited set of features such as the façade, interior finishes etc. would ever need to change from one project to another resulting in greater cost savings for healthcare developments. Some new major hospitals and medical research facilities in Melbourne, Australia have also used offsite manufactured concrete-infilled wall panel systems enabling a faster and more efficient construction process.

\subsection{Other Infrastructure Facilities}

Various government institutes in Australia have in recent times invested in offsite manufactured building products in constructing public facilities such as police stations, prisons and similar correctional facilities (Figures $5 \& 6$ ). The repetitive nature of their designs has again enabled volumetric modules to be used time efficiently and cost effectively

\section{Contributions from Multi-disciplinary Research}

\subsection{Architectural Design}

The authors are engaged in research that aims to design and develop a sustainable, prefabricated hybrid modular system that fosters mass customisation to achieve variety and individuality in low and mid-rise projects (Gunawardena et al., 2016 a).

The proposed modular system with standardisation of modular components is intended to achieve interchangeability of parts, simplicity of connections, consistent sizes and predictable and repetitive assembly processes. 
The abovementioned research will account for;

- Design novelty for flexible and smart modular and hybrid systems using state of the art parametric modelling techniques

- Achievable building specifications to sustainability measures

- Compliant and efficient structural and MEP (mechanical electrical and plumbing) performance

- BIM (building information modelling) and Lean manufacturing and assembly for overall process coordination and DfMA (Design form manufacturing and assembly).

The key technical challenge in this research is foreseen as overcoming the inherent limitations and developing a modular space system for diverse building applications. The new prefabricated paradigm offers the promising features of modern manufacturing and construction techniques with integration of several approaches previously overlooked including; modular flexibility, quick assembly, affordability, integrated building services, consistency, standardisation, automated manufacturing and predictable environmental control. The newly introduced mass customisation techniques are intended to remodel the prefabricated housing market in Australia. The current need for public housing in Victoria demand for such Architectural innovations and this research is working alongside such initiatives in developing efficient solutions. It has also assisted in developing repetitive template designs for rural public schools of Victoria which are planned in the second stage of the PMSB programme which was mentioned previously in section 3.1.

\subsection{Structural Analysis and Design}

A great amount of research is currently continuing with the involvement of the authors and many industry partners on the structural behaviour and performance of low rise and multistorey prefabricated buildings. Modular (volumetric) structural systems have been investigated in great detail in this regard.

Prefabricated modules can be categorised into two main forms according to their load transfer mechanisms;

1. Load-bearing modules $\rightarrow$ the perimeter wall structure of the module transfers the gravity loads to the modules below. This system is only feasible with low-rise applications.

2. Corner-supported modules $\rightarrow$ externally connected columns in the module take up the floor loads and transfer them to the columns below. This system is also capable of resisting horizontal loads such as earthquake and wind forces, thus ideal for multistorey applications.

Most multi-storey modular buildings around the world can be observed as systems of corner-supported modules that are connected laterally to a cast in-situ concrete or prefabricated steel core which eventually acts as the primary lateral load resisting element. Further, in most instances, the floors are poured with concrete subsequent to placing the modules. Although these methods were quite innovative at the time by saving construction time and cost initially, they did not define the structure as a purely modular construction. As a result, these structures would not fully enjoy the previously presented benefits of modular construction especially in terms of reusability. Once the floors are cast in-situ with concrete they would only be able to be removed by means of demolition. This concept of reusability is practiced now in the previously mentioned PMSB and PTV programmes. Many of those modules are intended to be removed, relocated and reused with minimum modifications in different future projects after serving its initial purpose for 15 to 20 years.

Table 1: Earthquake ground motions used to generate demand curves

\begin{tabular}{c|c|c|c|c|c}
\hline $\begin{array}{c}\text { Earthquake } \\
\text { Record }\end{array}$ & $\begin{array}{l}\text { Magnitude } \\
\text { (Moment } \\
\text { Magnitude } \\
\text { Scale) }\end{array}$ & Duration & $\begin{array}{c}\text { Time } \\
\text { Step }\end{array}$ & PGA & Scale \\
\hline Chi chi & 7.63 & $90.0 \mathrm{~s}$ & $0.005 \mathrm{~s}$ & $0.278 \mathrm{~g}$ & 1 \\
\hline Düzce & 7.14 & $25.8 \mathrm{~s}$ & $0.005 \mathrm{~s}$ & $0.535 \mathrm{~g}$ & 1 \\
\hline $\begin{array}{c}\text { Imperial } \\
\text { Valley }\end{array}$ & 6.90 & $40.0 \mathrm{~s}$ & $0.005 \mathrm{~s}$ & $0.519 \mathrm{~g}$ & 1 \\
\hline Kocaeli & 7.40 & $27.5 \mathrm{~s}$ & $0.005 \mathrm{~s}$ & $0.312 \mathrm{~g}$ & 1 \\
\hline $\begin{array}{c}\text { Loma } \\
\text { Prieta }\end{array}$ & 7.10 & $60.0 \mathrm{~s}$ & $0.005 \mathrm{~s}$ & $0.371 \mathrm{~g}$ & 1 \\
\hline Tabas & 7.40 & $16.0 \mathrm{~s}$ & $0.005 \mathrm{~s}$ & $0.852 \mathrm{~g}$ & 1 \\
\hline
\end{tabular}

Figure 7: Outcome of the capacity spectrum analysis 5\% damped demand curves against capacity curve (Gunawardena et al., 2016 b)

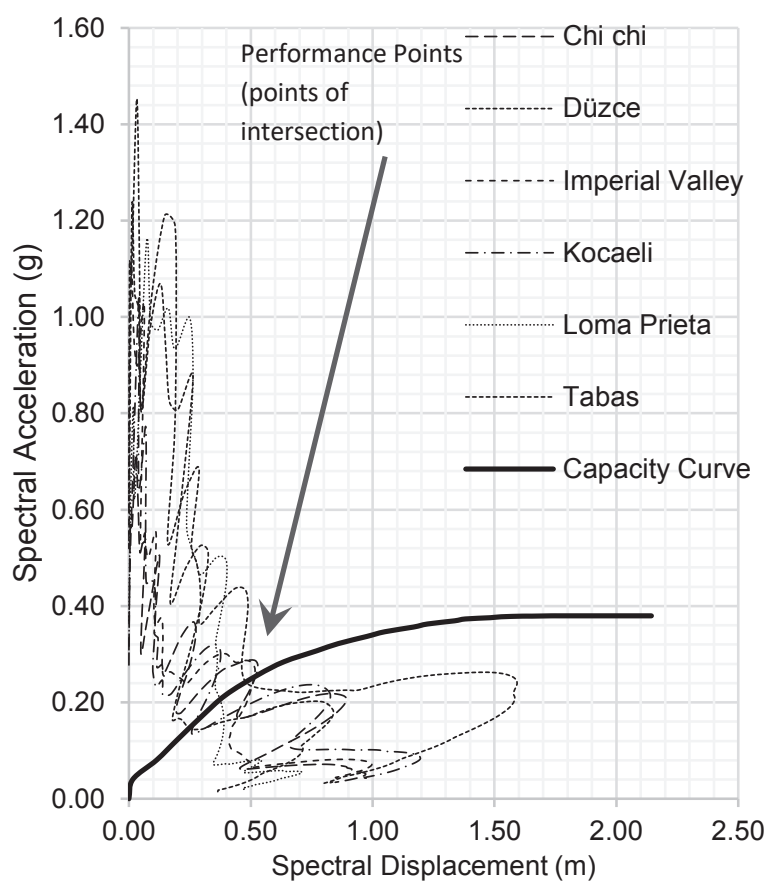


Gunawardena et al. (2016 b) introduced a modified cornersupported structural system where an assembly of prefabricated modules alone could be used to engineer a structurally stable building, which in turn will reward the building with full benefits of modular construction. A cast insitu or prefabricated core is not required to be the predominant lateral load resisting component in this structural system. The elevator shaft in this system is intended to be formed with steel elements as a part of some of the prefabricated modules themselves and therefore will not be the central component in the lateral load resisting system. The prefabricated modules are stacked vertically and connected horizontally through bolted plates. These connections need to be designed to take the full amount of shear forces generated by the design lateral loads.

Therefore, lateral load transfer mechanism is provided primarily through these connections and improved greatly through the introduction of modules with stiff concrete walls. These stiff modules which are strategically placed in the main structure resist the majority of lateral loads and transfer them down to the foundation. As a result, the structure would not require a traditional central structural core anymore. The structure would now be able to act as a purely modular system.

This new system provides architects with a great degree of freedom with a structure that is not limited by the placement of a core. The structural behaviour of this system was critically evaluated through recent research and since it is a cornersupported system its performance against lateral loads such as earthquake forces was also analysed as a key performance criterion. A capacity spectrum analysis was carried out on a hypothetical ten-storey building (Figure 7) constructed with this new corner supported system to obtain an indication of the system's performance against earthquake loads. Table 1 shows the six ground motion records that were used to generate the demand curves. While Gunawardena et al. (2016 b) discusses the seismic performance of the system in detail, Figure 5 shows a summarised outcome of the abovementioned capacity spectrum analysis. The analysis was carried out with the aid of the software RUAUMOKO 3D.

The outcome of the capacity spectrum analysis (Figure 7) concluded that the structure was past its linear deformation zone at its performance points against all six earthquake time histories. The performance points were also far below the full capacity of the structure. Therefore, it was deduced that the structure performed approximately in the 'Immediate Occupancy' to 'Life Safety' zone as per the performance levels described in FEMA 356 (2000). This is a valuable preliminary estimate of the performance of this structural system against the earthquakes loads. This research is currently progressing in assessing and developing new structural systems for multi storey structural systems that can be used for public schools such as the PMSB programme and housing projects in Australia.

\subsection{Energy Performance}

A fair amount of previous research has established a sound understanding of the energy performance of modular buildings. Aye et al. (2012) compared conventional concrete construction to modular steel and timber construction methods. This study involved an assessment of the embodied and operational energy associated with the particular building, for the mentioned three construction approaches. The operational energy assessment also included a lifecycle energy analysis and a lifecycle greenhouse gas emissions estimation for both operational energy and embodied energy related emissions. This particular research showed that the modular buildings performed much better in all the above-mentioned aspects

Figure 8: Total volume, mass and embodied energy of concrete and prefabricated steel and timber building scenarios, with percentage of potential savings achieved from the reuse of materials through Modular Construction

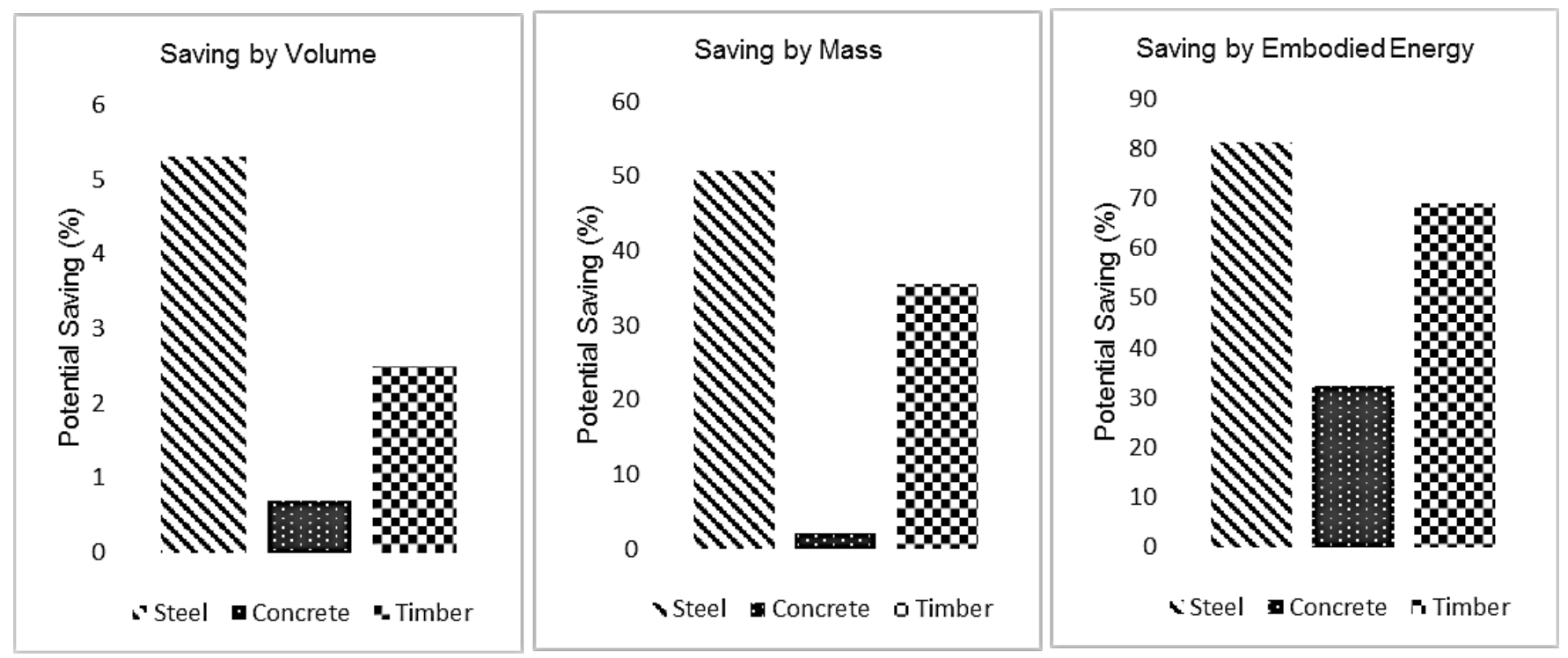


when their reusability was taken into consideration. A summary of the outcome of this research is shown in Figure 8. The graph highlights the considerably higher energy savings by volume, mass and embodied energy of the modular steel and timber structures compared to the conventional concrete structure.

This research is currently being extended in assisting with the previously mentioned PMSB programme in assessing the energy performance and indoor environmental quality of newly designed and built modular classroom buildings in many schools. It is also intended to provide a comparison between the performance of these new buildings and that of the older classroom buildings built with traditional methods.

\section{Concluding Remarks}

A country such as Australia with a high population growth rate in its major cities will generate a large number of public infrastructure projects and most of them would require rapid construction to avoid financial and practical difficulties. With challenges, such as depleting skilled labour resources and increasing construction costs, offsite manufacturing has emerged as a necessary yet beneficial feature of building construction. Modular construction in particular, provides designers, builders and developers with a means to realise challenging projects in a very short time with many other advantages.

Modular technology in particular has created a remarkable shift in modern construction from trying to make on-site activities safer and more efficient to making efficient offsite manufacturing (OSM), prototyping and assembly systems. This concept of Design for Manufacturing and Assembly (DfMA) is developing in the construction industry very strongly in creating better performing modular building systems which are delivering projects even faster and serving the public with minimum interruptions. In addition to faster constructions, it also creates a more quality oriented production practice and a safer working environment for well-trained building technicians. The work place of a construction worker would no longer be a sun-burnt, dust-filled construction site, but a healthy and safe production facility.

The examples discussed in this paper show the nature of real outcomes of using offsite manufactured buildings and components in delivering both small-scale and large-scale public infrastructure projects. Many other developed and developing countries too have successfully used offsite manufacturing in public infrastructure projects. The involvement of academic research is also highly encouraged by both government and private enterprises in Australia which is currently bearing fruit for many. It is therefore a great example of combining academic research with government initiatives in successfully carrying out public infrastructure projects and serving the general public in improving the overall quality of their daily lifestyle.

\section{Acknowledgements}

This work was funded by the ARC Training Centre for Advanced Manufacturing of Prefabricated Housing [Grant ID: IC150100023].

\section{References}

Aye L et al. (2012) Life cycle greenhouse gas emissions and energy analysis of prefabricated reusable building modules. Energy and Buildings, 47(0), 159-168.

Federal Emergency Federal Agency, FEMA-356 (2000) Prestandard and Commentary for Seismic Rehabilitation of Buildings. Washington DC

Gen7 (2018) https://www.gen7schools.com/projects/bishopelementary-school/ (accessed 10/11/2018)

Gunawardena T et al. (2014) Time Efficient Post Disaster Housing Reconstruction with Prefabricated Modular Structures. Open House International, 39(3), 59-66.

Gunawardena T et al. (2016 a) Innovative Flexible Structural System Using Prefabricated Modules. Journal of Architectural Engineering. 22(2), American Society of Civil Engineers

Gunawardena T et al. (2016 b) Behaviour of Multi-Storey Prefabricated Modular Buildings under seismic loads. Earthquakes and Structures. 11(6), pp. 1061-1076. Techno Press.

Lawson RM et al. (2012) Application of Modular Construction in High-rise Buildings. Journal of Architectural Engineering, 148-154. American Society of Civil Engineers.

Lusby-Taylor P et al. (2004) Design and Modern Methods of Construction, The Commission for Architecture and the Built Environment (CABE), London.

Modular Building Systems (2018) http://mbs.com.au/sectors/prison-cells/ (accessed 11/11/2018)

Navaratnam S et al. (2019) Performance Review of Prefabricated Building Systems and Future Research in Australia. Buildings, 9 (2), 38, doi:10.3390/buildings9020038 National Audit Office, UK (2005) Using modern methods of construction to build more homes quickly and efficiently

Prebuilt Pty. Ltd. (2018) https://www.prebuilt.com.au (accessed 10/11/2018)

Victorian School Building Authority (VSBA) (2018) https://www.schoolbuildings.vic.gov.au/Pages/PermanentModular-School-Buildings-Program.aspx (accessed $11 / 11 / 2018$ 